\title{
Community composition and seasonal changes of archaea in coarse and fine air particulate matter
}

\author{
Jörn Wehking ${ }^{1,2}$, Daniel A. Pickersgill ${ }^{1,2}$, Robert M. Bowers ${ }^{3,4}$, David Teschner $^{1,2}$, Ulrich Pöschl $^{2}$, \\ Janine Fröhlich-Nowoisky ${ }^{2}$, and Viviane R. Després ${ }^{1,2}$ \\ ${ }^{1}$ Institute of Molecular Physiology, Johannes Gutenberg University, Johannes-von-Müller-Weg 6, 55128 Mainz, Germany \\ ${ }^{2}$ Max Planck Institute for Chemistry, P.O. Box 3060, 55020 Mainz, Germany \\ ${ }^{3}$ DOE Joint Genome Institute, Walnut Creek, CA, USA \\ ${ }^{4}$ University of Colorado, Ecology and Evolutionary Biology, Boulder, CO, USA
}

Correspondence: Viviane R. Després (despres@uni-mainz.de) and Jörn Wehking (wehking@uni-mainz.de)

Received: 1 December 2017 - Discussion started: 14 December 2017

Revised: 11 June 2018 - Accepted: 15 June 2018 - Published: 11 July 2018

\begin{abstract}
Archaea are ubiquitous in terrestrial and marine environments and play an important role in biogeochemical cycles. Although air acts as the primary medium for their dispersal among different habitats, their diversity and abundance is not well characterized. The main reason for this lack of insight is that archaea are difficult to culture, seem to be low in number in the atmosphere, and have so far been difficult to detect even with molecular genetic approaches. However, to better understand the transport, residence time, and living conditions of microorganisms in the atmosphere as well as their effects on the atmosphere and vice versa, it is essential to study all groups of bioaerosols. Here we present an in-depth analysis of airborne archaea based on Illumina sequencing of 16S rRNA genes from atmospheric coarse and fine particulate matter samples and show seasonal dynamics and discuss anthropogenic influences on the diversity, composition, and abundance of airborne archaea.

The relative proportions of archaea to bacteria, the differences of the community composition in fine and coarse particulate matter, and the high abundance in coarse matter of one typical soil related family, the Nitrososphaeraceae, point to local phyllosphere and soil habitats as primary emission sources of airborne archaea.

We found comparable seasonal dynamics for the dominating Euryarchaeota classes and Crenarchaeota orders peaking in summer and fall. In contrast, the omnipresent Cenarchaeales and the Thermoplasmata occur only throughout summer and fall. We also gained novel insights into archaeal composition in fine particulate matter $(<3 \mu \mathrm{m})$, with $\mathrm{Ce}$ -
\end{abstract}

narchaeaceae, Nitrososphaeraceae, Methanosarcinales, Thermoplasmata, and the genus Nitrosopumilus as the dominating taxa.

The seasonal dynamics of methanogenic Euryarchaeota point to anthropogenic activities, such as fertilization of agricultural fields with biogas substrates or manure, as sources of airborne archaea. This study gains a deeper insight into the abundance and composition of archaea in the atmosphere, especially within the fine particle mode, which adds to a better understanding of the overall atmospheric microbiome.

\section{Introduction}

In addition to bacteria and eukaryotes, archaea constitute one of the three independent domains of life (Woese et al., 1990). In the beginning of archaeal research in the 1880s, primarily methanogenic archaea were discovered and cultivated, so the belief arose that archaea are exclusively extremophiles (Cavicchioli, 2011; Farlow, 1880; Schleper et al., 2005). However, during the last decades, cultivation- and culture-independent methods, such as DNA sequencing, have substantially improved the understanding of archaea and proved that they are also abundant in various environments such as marine or soil habitats, where they can represent more than $10 \%$ of the microbial community (Buckley et al., 1998; Cao et al., 2012; Cavicchioli, 2011; Delong, 1998; Robertson et al., 2005; Yilmaz et al., 2016). 
So far, diversity studies for archaea have mainly concentrated on the major habitats also known for bacteria such as marine and soil environments (Bintrim et al., 1997; Buckley et al., 1998; DeLong, 1992; Ochsenreiter et al., 2003). In the global marine environment the abundance of archaea is approximately $1 \times 10^{28}$ archaeal compared to $3 \times 10^{28}$ bacterial cells (Karner et al., 2001), with archaea accounting for $2-10 \%$ in surface waters and for $20-40 \%$ in deep ocean water (Massana et al., 1997).

The abundance and composition of archaea in soil vary between different soils types (Bates et al., 2011). All cultivated methanogens belong to the kingdom Euryarchaeota and are strictly dependent on anaerobic conditions with low redox potentials (Le Mer and Roger, 2010); thus, they are only present in small numbers in many soils. The fertilization with livestock manure adds anaerobically adapted organisms to the surface of agriculturally used soils. Thus, even in aerated soils, core anaerobic populations seem to survive albeit in low number (Angel et al., 2012). Another issue influencing the abundance and composition of archaea in soil is - as also observed in water columns - the depth (Karner et al., 2001). Analyses of soil depth profiles revealed changing diversity patterns with depth (Bundt et al., 2001; Pesaro and Widmer, 2002) in composition and number.

Next to the well-established major habitats, the atmosphere is another environment in which microorganisms can be detected; however, it remains unclear whether the atmosphere can be considered a natural habitat or whether it only represents a medium of dispersal for terrestrial and marine microorganisms and their spores (Bowers et al., 2009, 2011, 2012, 2013; Smith et al., 2013; Womack et al., 2010; Yooseph et al., 2013). For airborne bacteria and archaea the main known emission sources are surface waters and the surface layer of soils (Womack et al., 2010). Therefore, the different abundances and composition of archaea within water and soil columns are of special interest to understand possible emission sources for airborne archaea. For bacteria, which are abundant in air, the concentration of 16S rRNA gene copies quantified using qPCR in soil was $10^{11}$ to $10^{12}$ gene copies kg-1 and for archaea $10^{9}$ to $10^{11}$ gene copies kg-1 (Cao et al., 2012; Kemnitz et al., 2007). In ocean surface waters the concentration is lower but estimated to be $10^{8}$ to $10^{9}$ gene copies $\mathrm{L}^{-1}$ for bacteria and $10^{6}$ to $10^{7}$ gene copies $\mathrm{L}^{-1}$ for archaea (Kemnitz et al., 2007; Yin et al., 2013), whereas only $10^{4}$ to $10^{6}$ bacterial gene copies $\mathrm{m}^{-3}$ air have been detected (Cao et al., 2012; Fröhlich-Nowoisky et al., 2014; Kemnitz et al., 2007; Yin et al., 2013). Interestingly, in contrast to bacteria, it seems challenging to detect, amplify, and analyze archaea in air, as their concentration of $100 \mathrm{ppm}$ is much lower than the abundance of bacteria (Cao et al., 2012; Fröhlich-Nowoisky et al., 2014). Until now, it remains unclear whether these observations are biased by technical obstacles or reflect the true abundances. The largest study on airborne archaea is to our knowledge by Fröhlich-Nowoisky et al. (2014) and is based on Sanger sequencing. However, in Fröhlich-Nowoisky et al. (2014) the number of sequences were low, the observations had little statistical support, and the analysis of the microbiome of aerosolized archaea was difficult. Therefore, we present an in-depth next-generation sequencing study of airborne archaea collected on coarse and fine particulate matter filters over 1 year in Mainz, Germany. We attempt to compare the composition, diversity, and abundance to the same characteristics as in other habitats, which also allows an inference about the primary emission sources of airborne archaea.

\section{Material and methods}

\subsection{Aerosol sampling}

As described in Fröhlich-Nowoisky et al. (2009), in total 24 pairs of air filter samples (i.e., 20 filter pairs of one fine and one coarse particle filter sample each, 2 pairs of startup air filter blanks, and 2 pairs of mounting filter blanks) were analyzed within this dataset. The air filters were installed on an in-house-built high-volume dichotomous sampler (Solomon et al., 1983). The whole sampling campaign lasted 1 year in Mainz, Germany (March 2006-April 2007). The rotary vane pump (Becker VT 4.25) worked with a flow rate of $\sim 0.3 \mathrm{~m}^{3} \mathrm{~min}^{-1}$. The particles were split according to their aerodynamic diameter by a virtual impactor. Particles with an aerodynamic diameter larger than the nominal cut-off of $\sim 3 \mu \mathrm{m}$ and, due to the sampling device, an additional $10 \%$ of the fine particles were sampled in line with the inlet on one glass fiber filter (flow rate: $\sim 0.03 \mathrm{~m}^{3} \mathrm{~min}^{-1}$ ) representing the coarse fraction. The fine particles were collected on a second glass fiber filter perpendicular to the inlet $\left(\sim 0.27 \mathrm{~m}^{3} \mathrm{~min}^{-1}\right)$ which was essentially free from coarse particles (Solomon et al., 1983). To get a representative dataset for the whole year, five random samples, consisting of a coarse and fine filter, were analyzed for each of the four seasons of the sampling campaign. The sampling period of a single filter pair was generally 7 days except for filter pairs MZ 11 (24 h), MZ 15 (5 days), and MZ 31 (5 days; Table S1 in the Supplement). The sampled air masses represent a mixture of urban and rural continental air, as the sampler was positioned on the roof of the Max Planck Institute for Chemistry on the campus of the University of Mainz (49 $59^{\prime} 31.36^{\prime \prime} \mathrm{N}$, $\left.8^{\circ} 14^{\prime} 15.22^{\prime \prime} \mathrm{E}\right)$. To reduce the sampling of particles emitted from the ground, the sampling device was on a mast about $5 \mathrm{~m}$ above the flat roof of the three-story building.

\subsection{Extraction, amplification, and sequencing}

The DNA extraction and sequencing was part of the Earth Microbiome Project (EMP - http://www.earthmicrobiome. org/, last access: 4 November 2016) using the MoBio PowerMag Soil DNA Isolation kit and the Illumina GAIIx sequencer with the sequencing by synthesis technology. As shown before, this technology is suitable for analyzing mi- 
crobial communities in soil, water, and human skin (Caporaso et al., 2011).

For the PCR amplifications the 515f/806r primer set (Fwd: GTGCCAGCMGCCGCGGTAA; Rev: GGACTACHVGGGTWTCTAA) described in Caporaso et al. (2011) proved to be suitable, as shown by Bates et al. (2011). It covers the conserved flanking regions ideal for amplifying bacteria and archaea over the V4 region of the 16S rRNA gene (Bowers et al., 2013; Huse et al., 2008; Muyzer et al., 1993). In addition, the primer pair is preferred for this amplification as it exhibits only few biases against individual bacterial taxa. As suggested in Caporaso et al. (2011) each DNA extract was amplified in triplicate. These triplicates were combined and purified using a 96-well PCR clean-up kit from MO BIO. The utilized PCR reaction was performed; amplicons were purified and sequenced using the GAIIx.

\subsection{Grouping of sequences into OTUs and taxonomic identification}

The sequences were analyzed using the Quantitative Insight Into Microbial Ecology (QIIME) toolkit (Caporaso et al., 2010). To assign sequences to operational taxonomic units (OTUs), we used QIIME's closed reference OTU picking script, which uses Uclust (Edgar, 2010) and the Greengenes reference database (gg_13_8_otus/rep_set/97_otus.fasta, last update 15 August 2013; McDonald et al., 2012) with $97 \%$ similarity. For the actual identification process a corresponding taxonomy map provided by the Greengenes database was used. Sequences, which did not match to any Greengenes reference set OTU, were discarded for the downstream analysis.

\subsection{Controls}

Prior to the sampling procedure all filters were baked in sealed aluminum foil bags overnight at $500{ }^{\circ} \mathrm{C}$. To best conserve the DNA of the collected bioaerosols, after the sampling procedure all filter samples were stored at $-80^{\circ} \mathrm{C}$ until analysis. To detect possible contaminants from the sampling device and the filter handling, blank filters were taken at 4-week intervals. Contamination-free, prebaked filter pairs were mounted on the sampler as for regular sampling, but the pump was not turned on at all (mounting blanks). In addition, small environmental samples were taken to collect air exclusively around and from the interior of the sampling device by turning the pump on for $5 \mathrm{~s}$ only (start-up filter blanks). A detailed list of all analyzed air and blank filter samples with their individual sampling details can be found in the Supplement in Tables S1 and S2.

The DNA of the blank filters was extracted and quantified in parallel to the actual filter samples. Often, the detected DNA concentrations on blanks can be too small to be quantified or to build usable sequencing libraries (Cao et al., 2014). However, as the start-up blanks were briefly ex- posed to environmental air, they also could contain DNA. Within this study we controlled the actual filter changing process by sequencing two mounting blanks, i.e., MZ 23 and MZ 73. Two sequences were obtained from the fine particle filter of MZ 23 and 408 archaeal sequences (371 sequences on the coarse particle blank filter and 37 sequences on the fine particle blank filter) were detected on $M Z 73$. On the coarse particle filter of MZ 23 no archaeal sequences were detected. Minimal DNA amounts are to be expected, as the mounting blanks were briefly exposed to the air during the mounting process. The sequences on the mounting blanks were assigned to five archaeal families (Cenarchaeaceae, Methanobacteriaceae, Methanoregulaceae, Methanosaetaceae, Methanomassiliicoccaceae). The handling of the sequences obtained with next-generation sequencing techniques, e.g., for amplicon sequencing of environmental air sample controls, is neither well established nor standardized. To ensure that all contaminants were removed comprehensively from the dataset, we decided to omit all identified families from the data if present in more than $1 \%$ of all detected archaeal sequences of the mounting blanks.

The subsequently deleted families (from 404 sequences) Methanoregulaceae (8.5\%, 3 OTUs), Methanomassiliicoccaceae $(17.6 \%, 3$ OTUs), and the largest family of the Methanobacteriaceae $(72.4 \%, 4$ OTUs) all belonged to the Euryarchaeota (see also Table S2). In total 2341 sequences remained for the downstream analysis.

Likewise, two pairs of start-up air filter blanks were sequenced. But as they sampled the air for $5 \mathrm{~s}$ the obtained sequences were not treated like the mounting blanks. On these four filter samples 709 archaeal sequences were found, distributed with 328 sequences on MZ 22 (326 sequences on coarse, 2 sequences on fine) and 381 sequences on MZ 72 (3 sequences on coarse, 378 sequences on fine).

\subsection{Statistical analysis}

All data management and most of the analyses were performed using a MySQL database and R statistics if not stated otherwise (R-Team, 2011).

To characterize the biodiversity of the archaea community and thus to approximate the likely diversity, several statistical parameters were calculated: species richness estimators, rarefaction curves, and community diversity indices using the software tool EstimateS (Colwell et al., 2012).

\subsection{Meteorological analysis}

As a possible correlation between the abundance of taxonomic ranks in an air mass and meteorological parameters can be either following a monotone or specifically a linear relationship, in this study the Pearson product-moment correlation coefficient $\left(r_{K}\right)$ testing for a linear regression and the Spearman's rank $\left(r_{\mathrm{R}}\right)$ for fine, coarse, and total suspended particles (TSPs) were used. The meteorological parameters 
tested were wind speed in $\mathrm{ms}^{-1}$ (average and maximum), temperature in ${ }^{\circ} \mathrm{C}$ (range and maximum), relative humidity in $\%$, and the sum of precipitation in $\mathrm{mm}$. The meteorological data were provided in hourly data for wind speed and halfhourly values for all other meteorological parameters by the ZIMEN Luftmessnetz of the Landesamt für Umwelt Wasserwirtschaft und Gewerbeaufsicht of Rhineland-Palatinate. All averages were calculated for the exact sampling periods (Table S1). The correlation analysis using the Pearson productmoment correlation coefficient $\left(r_{K}\right)$ and Spearman's rank $\left(r_{\mathrm{R}}\right)$ were calculated for different taxonomic levels, i.e., kingdom, phylum, and class level. Only results with $r_{K}$ or $r_{\mathrm{R}}$ over 0.5 or under -0.5 were interpreted. However, no significant correlations between the relative abundance and the meteorological factors were found.

\section{Results and discussion}

\subsection{Overall diversity}

To determine the archaeal diversity in air, 20 air filter pairs were sampled and analyzed for 1 year in Mainz, Germany. Each filter pair consists of one filter collecting particles with aerodynamic diameters smaller than $3 \mu \mathrm{m}$ (fine particulate matter) and one collecting primarily coarse particles, which are larger than $3 \mu \mathrm{m}$. On 39 (97.5\%) of the 40 analyzed filters (20 air filter pairs) archaeal DNA could be detected. In total 2341 sequences could be assigned to archaea (Table 1). More archaeal sequences were detected on coarse particle filters (109 sequences on average per sample) than on fine particle filters ( 8 sequences on average per sample) for which the number of sequences ranged from 0 to 42 . On all but one fine particle filter, MZ 81 sampled in December 2006, archaeal sequences were discovered. The highest number of sequences, i.e., 601, were detected on the coarse particle filter MZ 74 from November 2006. The 2341 archaeal sequences were assigned to 52 OTUs. Out of these OTUs, 17 OTUs were found in coarse as well as in fine particulate matter. As listed in Table 1 the coarse particle filters comprised 2180 sequences distributed among 41 OTUs, whereas only 161 sequences assigned to 28 OTUs were identified on the fine particle filters.

In total only $7 \%$ of all archaeal sequences stem from fine particle filters, whereas $93 \%$ stem from coarse particle filters. Specifically, on $75 \%$ of the coarse particle filters 20 or more archaeal sequences were found, while on $70 \%$ of the fine particle filters less than 6 archaeal sequences could be detected.

The community structures of both size fractions differ remarkably in composition (Fig. 1). In the fine fraction the genus Nitrosopumilus is the dominant taxon. This Thaumarchaeota genus shows a relative abundance of $33.5 \%$ over all archaea sequences found on all samples in fine particulate matter. The cultivable Nitrosopumilus maritimus is

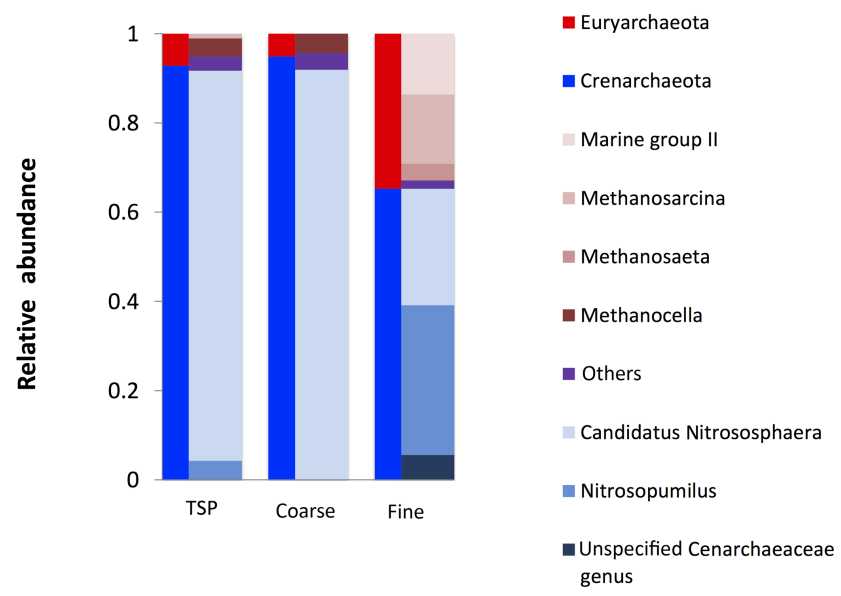

Figure 1. Archaeal community composition for total suspended (TSP), the same airstream split into coarse, and fine particulate matter on the level of phyla (red/blue) and genera (pastel colors).

a well-known representative of the genus Nitrosopumilus. These chemolithoautotrophic nitrifying archaea have primarily been sampled from marine sources. They form straight rods with a diameter of $0.17-0.22 \mu \mathrm{m}$ and a length of $0.5-$ $0.9 \mu \mathrm{m}$ (Könneke et al., 2005) and are thus one of the smallest organism known today. With this size even long-distance transport from marine sources might be conceivable. The same can be said for species of marine group II. However, $N$. maritimus and species of marine group II have been found in soil samples (Leininger et al., 2006; Treusch et al., 2005) - in contrast to the coarse fraction, where only the genera Methanocella and the Candidatus Nitrososphaera were found with relative proportions of more than $3 \%$. Due to the much higher number of sequences isolated from the coarse particle fraction in comparison to the fine fraction, the TSP composition resembles that of the coarse particle fraction (Fig. 1).

Taking the relative distribution over the entire course of the year into account, on class level the Thaumarchaeota also dominate the fine particle fraction, except fort two fine filters sampled during fall where the Euryarchaeota even have a higher relative abundance than the Thaumarchaeota (93 and $92 \%)$.

The Crenarchaeota, primarily represented by Thaumarchaeota $(99 \%)$, are the dominating phylum in the coarse particle mode. Next to Thaumarchaeota a single OTU of the miscellaneous Crenarchaeotal group (MCG; Kubo et al., 2012) representing seven sequences was found on a single coarse spring filter sample. No Euryarchaeota were observed on $65 \%$ of the fine particle filters and $50 \%$ of the coarse particle filters. A closer look at taxonomic assignments and the contribution of sequences to individual families reveals that most sequences within the coarse particle fraction belong to the Nitrososphaeraceae family. While this family is only present in $10 \%$ of the fine particle filters it was identified on $75 \%$ 
Table 1. Number of sequences and indices estimating the archaeal diversity in Mainz for coarse and fine particle filter samples and total suspended particles (TSPs).

\begin{tabular}{lrrrrrrr}
\hline Size fraction & $\begin{array}{r}n \\
\text { (Samples) }\end{array}$ & $\begin{array}{r}\mathrm{Sq} \\
\text { (Sequences) }\end{array}$ & $\mathrm{Sq} / n$ & $\begin{array}{r}\text { OTU } \\
\text { (operational } \\
\text { taxonomic unit) }\end{array}$ & $\begin{array}{r}S_{\text {Chao1 }} \\
\text { (Chao1) }\end{array}$ & $\begin{array}{r}H \\
\text { (Shannon) }\end{array}$ & $\begin{array}{r}D \\
\text { (Simpson) }\end{array}$ \\
\hline Coarse & 20 & 2180 & 109 & 41 & 64 & 3.09 & 0.83 \\
Fine & 20 & 161 & 8.1 & 28 & 41 & 3.65 & 0.88 \\
TSP & 20 & 2341 & 117.1 & 52 & 63 & 3.36 & 0.84 \\
\hline $\begin{array}{l}\text { Fröhlich-Nowoisky } \\
\text { et al. (2014) }\end{array}$ & 47 & 435 & 9.3 & 57 & 137 & 3.32 & 0.82 \\
\hline
\end{tabular}

of the coarse particle filters. In soil surveys the I.1.b group of Crenarchaeota has constantly been found (Ochsenreiter et al., 2003), with the Nitrososphaeraceae being one of the most abundant archaea families therein. Thus, the aerosolization of soil and soil dust as a primary source can be hypothesized for this family. Within this family the genus Nitrososphaera is an abundant taxon specifically in agricultural soils (Zhalnina et al., 2013). The landscape of the surrounding area of the sampling location is dominated by agricultural fields and the emitted soil particles are thus likely to contain the genus Nitrososphaera. Soil and soil dust are classically discussed as primary emission sources for airborne bacteria (Després et al., 2007, 2012; Fierer et al., 2008). Therefore, when attached to large soil particles these organisms should be mainly collected in the coarse particle fraction. To our knowledge, the only cultivated Nitrososphaera species, Nitrososphaera viennensis, has a much smaller diameter (irregular cocci with a diameter of 0.6-0.9 $\mu \mathrm{m}$; Stieglmeier et al., 2014), which should be, if in single cell status, collected in the fine particle mode. The hypothesis that soil particles identified through Nitrososphaeraceae are mainly collected on coarse particles is also strengthened by the results of community analysis of the fine particle filters. The observed increase of the relative abundance of the Euryarchaeota could also be interpreted as the decline of Nitrososphaeraceae as soil particles are less frequent in the fine mode. On the phylum level the Nitrososphaeraceae family forms the main difference between the two size fractions.

The diversity estimator Chaol (Table 1) and the rarefaction curves (Fig. 2) predict a relatively low diversity for archaea in Mainz air $\left(S_{\text {Chao } 1} ; 64\right.$ and 41 for coarse and fine, respectively). On the other hand, the relative abundances of the OTUs and the diversity calculated by Shannon $(H)$ or Simpson $(D)$ (Table 1) are slightly higher for the fine particle fraction. This might be because of the small sequence number but is surely driven by the relative dominance of $\mathrm{Ni}$ trososphaeraceae sequences in the coarse particulate matter (Fig. 1).

Most results of this study are in agreement with the previous Sanger-sequencing-based study by Fröhlich-Nowoisky et al. (2014), which analyzed 47 air filter pairs including

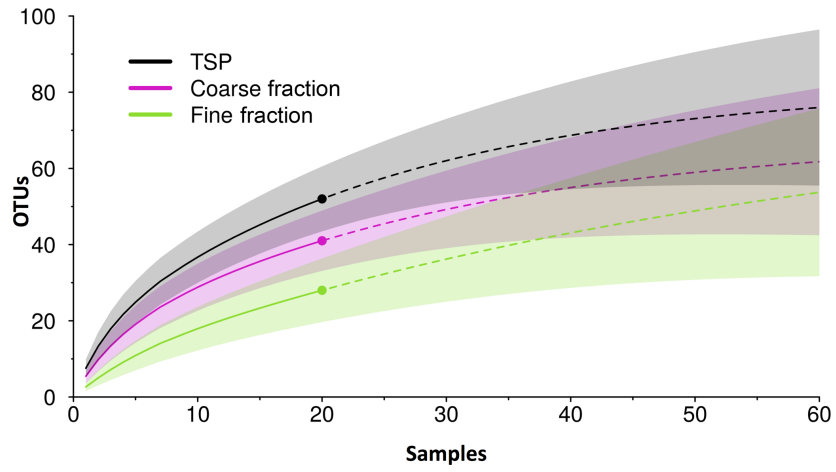

Figure 2. Rarefaction curve of species richness for total suspended (TSP), coarse, and fine particulate matter. TSP is a single airstream split into coarse and fine particulate matter. The solid curves represent the interpolated number of OTUs as a function against the number of samples. The dashed lines represent the extrapolations and the dots the sample size of this study. The colored areas represent the $95 \%$ confidence intervals.

the 20 filter pairs we focussed on in this study. However, in Fröhlich-Nowoisky et al. (2014), only a limited number of clones were sequenced, resulting in a total of 435 sequences, as compared to 2341 sequences obtained from the current study (Table 1). Fröhlich-Nowoisky et al. (2014) concluded that archaea occur far more often in coarse particulate matter than in fine particulate matter as archaeal DNA could only be detected on $21 \%$ of the fine particle filters, which is consistent with the results of this study. Another consistency compared to the study of Fröhlich-Nowoisky et al. (2014) is the high abundances for Group I.1.b on coarse particle samples. This can be explained by the higher relative abundance of Nitrososphaeraceae in the coarse particle fraction discovered in this study.

The main difference between the Sanger and the Illumina approach is the estimated species richness, with 137 species from Sanger estimating almost double the amount compared to the Illumina approach, which estimates 63 species. This can be caused by several issues: first, a possible lack of taxonomical depth caused by the shorter sequences compared to the Sanger approach and the usage of different primer pairs; 
second, by the closed-reference-based taxonomic assignment and a possible lack of taxonomical depth in the used reference dataset; and, third and most likely, by the smaller number of sequences from more filter samples used in FröhlichNowoisky et al. (2014).

As the used primers also amplified bacterial sequences, the following observation could be made. The ratio of archaea and bacteria suggests a very low proportion of airborne archaea in comparison to airborne bacteria (Fig. 3). In total, $0.07 \%$ of the total reads could be assigned to archaea, while the rest $\left(5.7 \times 10^{6}\right.$ reads $)$ consists of bacterial, mitochondrial, and plasmid DNA. After the sequences of mitochondria and plastids are eliminated, the ratio of archaea to bacteria increases only to $0.1 \%$, which is widely different from the ratios discovered in the soil and marine environment.

This extremely low ratio is an interesting phenomenon as in most possible emission sources the proportion of archaea is higher than in air.

Several studies, focusing on airborne bacteria and archaea, found that archaeal DNA in air is extremely low (Cao et al., 2014; Yooseph et al., 2013; Smith et al., 2013). Cao et al. (2014) found a proportion of $0.8 \%$ of archaea when compared to bacteria in $\mathrm{PM}_{10}$ and $\mathrm{PM}_{2.5}$ using Illumina HiSeq data (2014). Yooseph et al. (2013), who analyzed the urban prokaryotic metagenome of New York, on a multistep approach based on taxonomic classifications for their metagenomic reads and assigned to the different organism groups, found that $0.48 \%$ of their sequences were archaeal, with roughly $80 \%$ Euryarchaeota and $20 \%$ Crenarchaeota and Thaumarchaeota. Both studies therefore agree with the $0.1 \%$ archaeal sequences found in Mainz air.

Next to comparisons of species diversity and composition, the ratio of bacteria to archaea might be an indicator of the possible emission sources, as the aerosolization process is likely to equally affect all microorganisms from an emission source. We therefore compared the detected ratios with ratios of possible emission sources such as soils, surface water, and the phyllosphere reported in literature (Fig. 3).

We found that compared to soil the microbial habitat, which is often discussed as the primarily emission source, differs strongly from our and other air studies. Although archaeal abundance in aerated soils increases with depth (Kemnitz et al., 2007), the proportion known for surface soil is still much higher than the proportions in air. Thus, soil alone seems an unlikely emission source. Also in sea water their abundance increases with depth reaching up to $39 \%$ (Karner et al., 2001). As Mainz is not close to oceans, emission from sea water seems unlikely as a primary source. The only larger emission surface from water might be the river Rhine which is very likely one of the primary sources in the study area.

In a review by Vorholt (2012) it is convincingly shown that the abundance of archaea in the phyllosphere is less than $1 \%$ of the total microorganism load (Fig. 4), which is similar to the $0.1 \%$ we found. With a total area of $10^{9} \mathrm{~km}^{2}$ of the upper and smaller leaf surface, the phyllosphere sur-

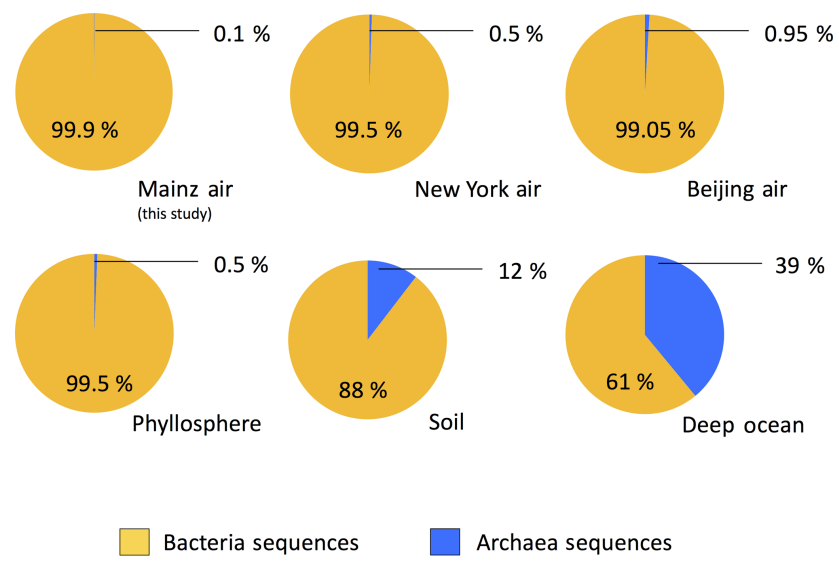

Figure 3. Relative proportions of archaeal (blue) and bacterial (yellow) sequences detected in environmental samples. Proportions for soil are based on Kemnitz et al. (2007), for the deep ocean on Karner et al. (2001), and for the phyllosphere on Delmotte et al. (2009) and Knief et al. (2012). The proportions of the Mainz air are based on this study. The data for the New York air are published in Yooseph et al. (2013) and the data of Beijing are based on Cao et al. (2014).

face habitat is approximately twice the size of the land surface and is supposed to comprise up to $10^{26}$ cells worldwide (Vorholt, 2012); therefore, it could present a significant emission source (Woodward and Lomas, 2004) in the studied area. Thus, the phyllosphere might be the local primary emission source.

The situation might, however, differ for individual groups found in the air filter samples, such as the Nitrososphaera family. This family includes typical soil microorganisms, which would point to soil as a primary emission source. The presence of this family in the air might be, on the one hand, caused by the diversity of the phyllosphere. Especially for annual plants, the microorganism diversity of the phyllosphere is primarily driven by soil and the soil microbiome surrounding the sampling site (Knief et al., 2010). On the other hand, the explanation especially for the findings in the coarse fraction is that larger soil particles carry many typical soil archaea. Thus, based on the proportions of bacteria and archaea, the most likely interpretation is that the microbiome detected in the Mainz air primarily originates from the phyllosphere and is complemented by small soil particles, which add a large amount of typical soil archaea. Unfortunately, there is a lack of literature on archaea of the phyllosphere; thus, the identification of the emission source based on the composition cannot be answered for certain.

Based on the identified genera, however, the phyllosphere and the soil can both be the primary emission source. But as the microbiome of the soil drives the composition of the phyllosphere, comparing taxonomy alone will not lead to a final answer. 


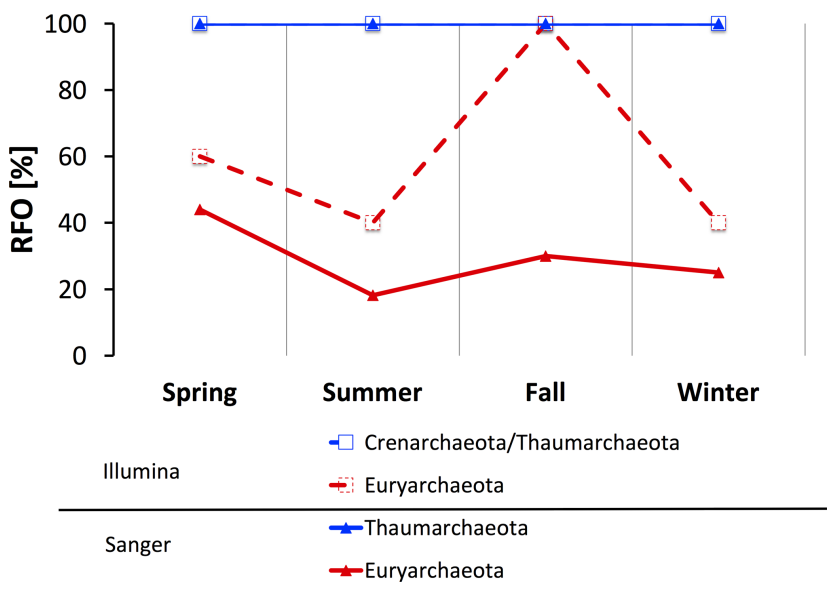

Figure 4. Seasonal variation in the relative frequency of occurrence (RFO) of airborne archaea on the phylum level. The relative frequency of occurrence - the proportion of samples in which these taxa were detected - is given for both phyla, i.e., Thaumarchaeota and Euryarchaeota. The graph based on Sanger sequencing represents the data published in Fröhlich-Nowoisky et al. (2014), whereas the remaining data comprises the results of this study.

\subsection{Seasonal dynamics}

To better understand the seasonal dynamics of archaea in the atmosphere the availability of emission sources over different seasons per year can be analyzed. As mentioned, from the 2341 archaeal sequences 168 could be assigned to Euryarchaeota. Based on their relative frequencies of occurrence (RFO), Thaumarchaeota are present all year, whereas Euryarchaeota are less abundant and their RFO values show seasonal peaks in spring and fall (Fig. 4).

Although the seasonal increasing or decreasing trends of the RFO values over the year are similar to FröhlichNowoisky et al. (2014), overall they are higher.

Fröhlich-Nowoisky et al. (2014) suggested the nearby river Rhine as a potential permanent source for Methanomicrobiales and Thermoplasmatales as they are known to be present in river water throughout the year (Auguet et al., 2009; Cao et al., 2013). The RFO values of the orders shown in Fig. 5 present a slightly different picture: Methanomicrobia were observed in every season with RFO values around $40 \%$; thus, the Rhine could contribute continuously to the aerosolized Methanomicrobia. However, the Thermoplasmata group was exclusively found in summer and fall samples, arguing against an emission from an omnipresent source like the Rhine.

Alternatively to the Rhine, potential emission sources for several groups of Euryarchaeota - especially in agricultural areas as around Mainz - are biogas substrates and livestock fertilization methods (Fröhlich-Nowoisky et al., 2014). Figure 5 shows that Methanomicrobia and Methanobacteria both have their highest relative RFO during fall and another increase during the springs in 2006 and 2007. This supports

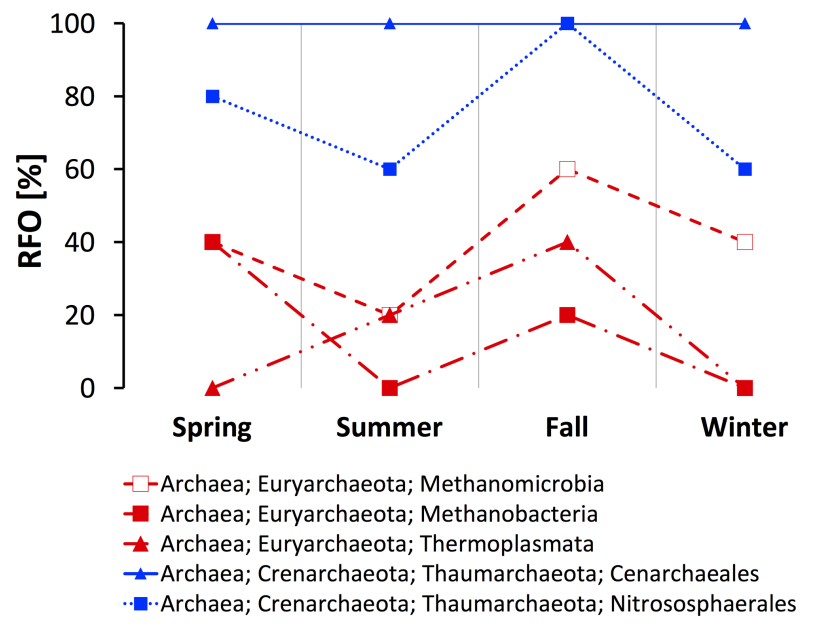

Figure 5. Seasonal variation in the relative frequency of occurrence of dominating Euryarchaeota classes and Crenarchaeota orders within this study.

the hypothesis, of livestock manure being a possible emission source, as both classes are commonly known to be present in the microbiome of livestock and the typical times for fertilization of fields with manure are in spring and fall (Nicol et al., 2003; Radl et al., 2007). As all methanogen groups, they have been reported in biogas reactors, too (Jaenicke et al., 2011). For the Thermoplasmata the peaks in summer and fall might be linked to the usage of biogas reactor substrates, which are also applied to agricultural fields as fertilizer. The differing RFO values of Thermoplasmata and other Euryarchaeota might be caused by their sensitivity to temperature and especially to $\mathrm{pH}$, which only allows their survival in moderate to high temperatures and low $\mathrm{pH}$ environments.

The hypothesis that aerosolized archaea are linked to agricultural activities is also supported by the seasonal variation of the RFO of the order of the Nitrososphaerales within the Thaumarchaeota that is also present in the Euryarchaeota classes as discussed. Nitrososphaerales were found in agricultural soil samples close to the sampling area of our study (Ochsenreiter et al., 2003; Zhalnina et al., 2013) and thus can be considered a typical agricultural soil microorganism.

\section{Conclusions}

This study gains a deeper insight into the diversity of airborne archaea. The overall abundance of archaea in the atmosphere compared to bacteria is very low, which is comparable to the ratio found for the phyllosphere. We found the Nitrososphaeraceae family out of the I.1.b group of Crenarchaeota to be the major archaeal family in coarse particulate matter. The groups Cenarchaeaceae, Nitrososphaeraceae, Methanosarcinales, and Thermoplasmata as well as the genus Nitrosopumilus could be observed within the fine particulate matter. 
The observed seasonal dynamics for the dominating Euryarchaeota classes and Crenarchaeota orders, which peak in summer and fall, might be a result of agriculture in the surrounding area. Therefore, anthropogenic activities like fertilization with livestock manure or substrates of biogas reactors might influence the diversity of airborne archaea as their occurrence is increased during the main fertilization seasons.

This combination of findings provides support for the conceptual premise that the occurrence of archaea in air might be driven by the microbiota of the phyllosphere but the influence of livestock manure gains an edge over the phyllosphere through the fertilization seasons. Additionally, groups emitted with soil as carrier particles seem to have a major influence on the community composition. For a further understanding of the dependencies of airborne microorganisms on their sources, future studies should additionally explore possible source habitats to gain as complete a picture as possible.

We conclude that the understanding of the seasonality, diversity, and composition of airborne archaea as one very small fraction within the bioaerosols is an important contribution to the understanding of the patterns driving the whole atmospheric microbiome.

Data availability. The post-library-split sequence dataset is available from the Edmond digital repository at: https://doi.org/10.17617/3.11 (Wehking et al., 2018).

\section{The Supplement related to this article is available online at https://doi.org/10.5194/bg-15-4205-2018-supplement.}

Author contributions. JW and VRD wrote the paper. VRD, UP, JF-N, DAP, JW, RMB, and DT designed the research. JF-N and RMB performed the sample collection and laboratory work. JW performed downstream analysis. JW and DAP performed correlations with meteorological data. All co-authors discussed the results, read and contributed to the manuscript.

Competing interests. The authors declare that they have no conflict of interest.

Acknowledgements. The authors are grateful to Isabell MüllerGermann, Hauke Paulsen, Carina Osterhof, and Cristina Ruzene Nespoli for their technical assistance, as well as Meinrat O. Andreae, Ralf Conrad, Pierre E. Galand, Mike Grant, and Robbin Stantscheff for their helpful discussions. We also thank the Mainz Bioaerosol Laboratory (MBAL) for their support. This work was supported by the Max Planck Society. Jörn Wehking acknowledges the $\mathrm{PhD}$ grant of the Konrad-Adenauer-Stiftung.
The article processing charges for this open-access publication were covered by the Max Planck Society.

Edited by: Denise Akob

Reviewed by: Baolan Hu and two anonymous referees

\section{References}

Angel, R., Claus, P., and Conrad, R.: Methanogenic archaea are globally ubiquitous in aerated soils and become active under wet anoxic conditions, ISME J., 6, 847-862, https://doi.org/10.1038/ismej.2011.141, 2012.

Auguet, J.-C., Barberan, A., and Casamayor, E. O.: Global ecological patterns in uncultured Archaea, ISME J., 4, 182-190, 2009.

Bates, S. T., Berg-Lyons, D., Caporaso, J. G., Walters, W. A., Knight, R., and Fierer, N.: Examining the global distribution of dominant archaeal populations in soil, ISME J., 5, 908-917, https://doi.org/10.1038/ismej.2010.171, 2011.

Bintrim, S. B., Donohue, T. J., Handelsman, J., Roberts, G. P., and Goodman, R. M.: Molecular phylogeny of Archaea from soil, P. Natl. Acad. Sci. USA, 94, 277-282, 1997.

Bowers, R. M., Lauber, C. L., Wiedinmyer, C., Hamady, M., Hallar, A. G., Fall, R., Knight, R., and Fierer, N.: Characterization of airborne microbial communities at a high-elevation site and their potential to act as atmospheric ice nuclei, Appl. Environ. Microbiol., 75, 5121-5130, https://doi.org/10.1128/AEM.0044709, 2009.

Bowers, R. M., McLetchie, S., Knight, R., and Fierer, N.: Spatial variability in airborne bacterial communities across landuse types and their relationship to the bacterial communities of potential source environments, ISME J., 5, 601-612, https://doi.org/10.1038/ismej.2010.167, 2011.

Bowers, R. M., McCubbin, I. B., Hallar, A. G., and Fierer, N.: Seasonal variability in airborne bacterial communities at a high-elevation site, Atmos. Environ., 50, 41-49, https://doi.org/10.1016/j.atmosenv.2012.01.005, 2012.

Bowers, R. M., Clements, N., Emerson, J. B., Wiedinmyer, C., Hannigan, M. P., and Fierer, N.: Seasonal variability in bacterial and fungal diversity of the near-surface atmosphere, Environ. Sci. Technol., 47, 12097-12106, 2013.

Buckley, D. H., Graber, J. R., and Schmidt, T. M.: Phylogenetic analysis of nonthermophilic members of the kingdom Crenarchaeota and their diversity and abundance in soils, Appl. Environ. Microbiol., 64, 4333-4339, 1998.

Bundt, M., Widmer, F., Pesaro, M., Zeyer, J., and Blaser, P.: Preferential flow paths: Biological "hot spots" in soils, Soil Biol. Biochem., 33, 729-738, https://doi.org/10.1016/S00380717(00)00218-2, 2001.

Cao, C., Jiang, W., Wang, B., Fang, J., Lang, J., Tian, G., Jiang, J., and Zhu, T. F.: Inhalable microorganisms in Beijing's $\mathrm{PM}_{2.5}$ and $\mathrm{PM}_{10}$ pollutants during a severe smog event, Environ. Sci. Technol., 48, 1499-1507, 2014.

Cao, H., Auguet, J.-C., and Gu, J.-D.: Global Ecological Pattern of Ammonia-Oxidizing Archaea, edited by: Bertilsson, S., PLoS One, 8, 1-8, https://doi.org/10.1371/journal.pone.0052853, 2013. 
Cao, P., Zhang, L. M., Shen, J. P., Zheng, Y. M., Di, H. J., and He, J. Z.: Distribution and diversity of archaeal communities in selected Chinese soils, FEMS Microbiol. Ecol., 80, 146-158, https://doi.org/10.1111/j.1574-6941.2011.01280.x, 2012.

Caporaso, J. G., Kuczynski, J., Stombaugh, J., Bittinger, K., Bushman, F. D., Costello, E. K., Fierer, N., Peña, A. G., Goodrich, J. K., Gordon, J. I., Huttley, G. A., Kelley, S. T., Knights, D., Koenig, J. E., Ley, R. E., Lozupone, C. A., Mcdonald, D., Muegge, B. D., Pirrung, M., Reeder, J., Sevinsky, J. R., Turnbaugh, P. J., Walters, W. A., Widmann, J., Yatsunenko, T., Zaneveld, J., and Knight, R.: QIIME allows analysis of highthroughput community sequencing data Intensity normalization improves color calling in SOLiD sequencing, Nat. Publ. Gr., 7, 335-336, https://doi.org/10.1038/nmeth.f.303, 2010.

Caporaso, J. G., Lauber, C. L., Walters, W. A., Berg-Lyons, D., Lozupone, C. A., Turnbaugh, P. J., Fierer, N., and Knight, R.: Global patterns of $16 \mathrm{~S}$ rRNA diversity at a depth of millions of sequences per sample, P. Natl. Acad. Sci. USA, 108 Suppl., 4516-4522, https://doi.org/10.1073/pnas.1000080107, 2011.

Cavicchioli, R.: Archaea - timeline of the third domain, Nat. Rev. Microbiol., 9, 51-61, https://doi.org/10.1038/nrmicro2482, 2011.

Colwell, R. K., Chao, A., Gotelli, N. J., Lin, S. Y., Mao, C. X., Chazdon, R. L., and Longino, J. T.: Models and estimators linking individual-based and sample-based rarefaction, extrapolation and comparison of assemblages, J. Plant Ecol., 5, 3-21, https://doi.org/10.1093/jpe/rtr044, 2012.

Delmotte, N., Knief, C., Chaffron, S., Innerebner, G., Roschitzki, B., Schlapbach, R., von Mering, C., and Vorholt, J.: Community proteogenomics reveals insights into the physiology of phyllosphere bacteria., P. Natl. Acad. Sci. USA, 106, 16428-16433, https://doi.org/10.1073/pnas.0905240106, 2009.

Delong, E. F.: Everything in moderation: Archaea as "nonextremophiles", Curr. Opin. Genet. Dev., 8, 649-654, https://doi.org/10.1016/S0959-437X(98)80032-4, 1998.

DeLong, E. F.: Archaea in coastal marine environments, P. Natl. Acad. Sci. USA, 89, 5685-5689, 1992.

Després, V. R., Nowoisky, J. F., Klose, M., Conrad, R., Andreae, M. O., and Pöschl, U.: Characterization of primary biogenic aerosol particles in urban, rural, and high-alpine air by DNA sequence and restriction fragment analysis of ribosomal RNA genes, Biogeosciences, 4, 1127-1141, https://doi.org/10.5194/bg-4-11272007, 2007.

Després, V. R., Alex Huffman, J., Burrows, S. M., Hoose, C., Safatov, A. S., Buryak, G., Fröhlich-Nowoisky, J., Elbert, W., Andreae, M. O., Pöschl, U., and Jaenicke, R.: Primary biological aerosol particles in the atmosphere: a review, Tellus B, 64, 1, https://doi.org/10.3402/tellusb.v64i0.15598, 2012.

Edgar, R. C.: Search and clustering orders of magnitude faster than BLAST, Bioninformatics, 26, 2460-2461, 2010.

Farlow, W.: On the Nature of the Peculiar Reddening of Salted Codfish during the Summer Season, United States Comm. Fish Fish. Part IV Rep. Comm. 1878., (XLIV), 969-974, 1880.

Fierer, N., Liu, Z., Rodríguez-Hernández, M., Knight, R., Henn, M., and Hernandez, M. T.: Short-term temporal variability in airborne bacterial and fungal populations, Appl. Environ. Microb., 74, 200-207, https://doi.org/10.1128/AEM.01467-07, 2008.

Fröhlich-Nowoisky, J., Pickersgill, D. A, Després, V. R., and Pöschl, U.: High diversity of fungi in air particu- late matter., P. Natl. Acad. Sci. USA, 106, 12814-12819, https://doi.org/10.1073/pnas.0811003106, 2009.

Fröhlich-Nowoisky, J., Ruzene Nespoli, C., Pickersgill, D. A., Galand, P. E., Müller-Germann, I., Nunes, T., Gomes Cardoso, J., Almeida, S. M., Pio, C., Andreae, M. O., Conrad, R., Pöschl, U., and Després, V. R.: Diversity and seasonal dynamics of airborne archaea, Biogeosciences, 11, 6067-6079, https://doi.org/10.5194/bg-11-6067-2014, 2014.

Huse, S. M., Dethlefsen, L., Huber, J. A., Welch, D. M., Relman, D., and Sogin, M. L.: Exploring microbial diversity and taxonomy using SSU rRNA hypervariable tag sequencing, PLoS Genet., 4, https://doi.org/10.1371/journal.pgen.1000255, 2008.

Jaenicke, S., Ander, C., Bekel, T., Bisdorf, R., Dröge, M., Gartemann, K. H., Jünemann, S., Kaiser, O., Krause, L., Tille, F., Zakrzewski, M., Pühler, A., Schlüter, A., and Goesmann, A.: Comparative and joint analysis of two metagenomic datasets from a biogas fermenter obtained by 454-pyrosequencing, PLoS One, 6, https://doi.org/10.1371/journal.pone.0014519, 2011.

Karner, M. B., DeLong, E. F., and Karl, D. M.: Archaeal dominance in the mesopelagic zone of the Pacific Ocean., Nature, 409, 507510, https://doi.org/10.1038/35054051, 2001.

Kemnitz, D., Kolb, S., and Conrad, R.: High abundance of Crenarchaeota in a temperate acidic forest soil, FEMS Microbiol. Ecol., 60, 442-448, https://doi.org/10.1111/j.1574-6941.2007.00310.x, 2007.

Knief, C., Ramette, A., Frances, L., Alonso-Blanco, C., and Vorholt, J. A.: Site and plant species are important determinants of the Methylobacterium community composition in the plant phyllosphere, ISME J., 4, 719-728, https://doi.org/10.1038/ismej.2010.9, 2010.

Knief, C., Delmotte, N., Chaffron, S., Stark, M., Innerebner, G., Wassmann, R., von Mering, C., and Vorholt, J.: Metaproteogenomic analysis of microbial communities in the phyllosphere and rhizosphere of rice, ISME J., 6, 1378-1390, https://doi.org/10.1038/ismej.2011.192, 2012.

Könneke, M., Bernhard, A. E., de la Torre, J. R., Walker, C. B., Waterbury, J. B., and Stahl, D. A.: Isolation of an autotrophic ammonia-oxidizing marine archaeon, Nature, 437, 543-546, https://doi.org/10.1038/nature03911, 2005.

Kubo, K., Lloyd, K. G., F Biddle, J., Amann, R., Teske, A., and Knittel, K.: Archaea of the Miscellaneous Crenarchaeotal Group are abundant, diverse and widespread in marine sediments, ISME J., 6, 1949-1965, https://doi.org/10.1038/ismej.2012.37, 2012.

Le Mer, J. and Roger, P.: Production, oxidation, emission and consumption of methane by soils: A review, Eur. J. Soil Biol., 37 , 25-50, 2010.

Leininger, S., Schloter, M., Schwark, L., Qi, J., Nicol, G. W., Prosser, J. I., Schuster, S. C., and Schleper, C.: Archaea predominate among ammonia-oxidizing prokaryotes in soils, Nature, 442, 806-809, 2006.

Massana, R., Murray, E., Preston, C. M., and DeLong, E. F.: Vertical distribution and phylogenetic characterization of marine planktonic Archaea in the Santa Barbara Channel, Appl. Environ. Microb., 63, 50-56, 1997.

McDonald, D., Price, M. N., Goodrich, J., Nawrocki, E. P., DeSantis, T. Z., Probst, A., Andersen, G. L., Knight, R., and Hugenholtz, P.: An improved Greengenes taxonomy with explicit ranks for ecological and evolutionary analyses of bacteria and archaea, 
ISME J., 6, 610-618, https://doi.org/10.1038/ismej.2011.139, 2012.

Muyzer, G., De Waal, E. C., and Uitterlinden, A. G.: Profiling of complex microbial populations by denaturing gradient gel electrophoresis analysis of polymerase chain reaction-amplified genes coding for 16S rRNA, Appl. Environ. Microbiol., 59, 695$700,1993$.

Nicol, G. W., Glover, L. A., and Prosser, J. I.: Molecular analysis of methanogenic archaeal communities in managed and natural upland pasture soils, Glob. Chang. Biol., 9, 1451-1457, https://doi.org/10.1046/j.1365-2486.2003.00673.x, 2003.

Ochsenreiter, T., Selezi, D., Quaiser, A., Bonch-Osmolovskaya, L., and Schleper, C.: Diversity and abundance of Crenarchaeota in terrestrial habitats studied by $16 \mathrm{~S}$ RNA surveys and real time PCR, Environ. Microbiol., 5, 787-797, https://doi.org/10.1046/j.1462-2920.2003.00476.x, 2003.

Pesaro, M. and Widmer, F.: Identification of novel Crenarchaeota and Euryarchaeota clusters associated with different depth layers of a forest soil, FEMS Microbiol. Ecol., 42, 89-98, https://doi.org/10.1016/S0168-6496(02)00302-1, 2002.

Radl, V., Gattinger, A., Chronáková, A., Nemcová, A., Cuhel, J., Simek, M., Munch, J. C., Schloter, M., and Elhottová, D.: Effects of cattle husbandry on abundance and activity of methanogenic archaea in upland soils, ISME J., 1, 443-452, https://doi.org/10.1038/ismej.2007.60, 2007.

Robertson, C. E., Harris, J. K., Spear, J. R., and Pace, N. R.: Phylogenetic diversity and ecology of environmental Archaea, Curr. Opin. Microbiol., 8, 638-642, https://doi.org/10.1016/j.mib.2005.10.003, 2005.

Schleper, C., Jurgens, G., and Jonuscheit, M.: Genomic studies of uncultivated archaea, Nat. Rev. Microbiol., 3, 479-488, https://doi.org/10.1038/nrmicro1159, 2005.

Smith, D., Timonen, J., Jaffe, D., Griffin, D., Birmele, M., and Roberts, M.: Intercontinental dispersal of bacteria and archaea by transpacific winds, Appl. Environ. Microbiol., 79, 1134-1139, 2013.

Solomon, P. A., Moyers, J. L., and Fletcher, R. A.: High-Volume dichotomous virtual impactor for the fractionation and collection of particles according to aerodynamic size, Aerosol Sci. Technol., 2, 455-464, 1983.

Stieglmeier, M., Klingl, A., Alves, R. J. E., Rittmann, S. K. M. R., Melcher, M., Leisch, N., and Schleper, C.: Nitrososphaera viennensis gen. nov., sp. nov., an aerobic and mesophilic, ammoniaoxidizing archaeon from soil and a member of the archaeal phylum Thaumarchaeota, Int. J. Syst. Evol. Microbiol., 64, 27382752, https://doi.org/10.1099/ijs.0.063172-0, 2014.
Team, R. D. C.: R: a language and environment for statistical computing, R Foundation for Statistical Computing, available at: http://www.r-project.org/, 2011.

Treusch, A. H., Leininger, S., Kletzin, A., Schuster, S. C., Klenk, H.-P., and Schleper, C.: Novel genes for nitrite reductase and Amo-related proteins indicate a role of uncultivated mesophilic crenarchaeota in nitrogen cycling, Environ. Microbiol., 7, 19851995, https://doi.org/10.1111/j.1462-2920.2005.00906.x, 2005.

Vorholt, J. A: Microbial life in the phyllosphere, Nat. Rev. Microbiol., 10, 828-40, https://doi.org/10.1038/nrmicro2910, 2012.

Wehking, J., Pickersgill, D. A., Bowers, R. M., Teschner, D., Pöschl, U., Fröhlich-Nowoisky, J., and Després, V. R.: Illumina sequences of 16S-rRNA from atmospheric coarse and fine particulate matter samples, available at: https://doi.org/10.17617/3.11, 2018.

Woese, C. R., Kandler, O., and Wheelis, M. L.: Towards a natural system of organisms: Proposal for the domains Archaea, Bacteria, and Eucarya, P. Natl. Acad. Sci. USA, 87, 4576-4579, 1990.

Womack, A. M., Bohannan, B. J. M., and Green, J. L.: Biodiversity and biogeography of the atmosphere., Phil. Trans. R. Soc. B, 365, 3645-3653, https://doi.org/10.1098/rstb.2010.0283, 2010.

Woodward, F. I. and Lomas, M. R.: Vegetation dynamics-simulating responses to climatic change, Biol. Rev. Camb. Philos. Soc., 79, 643-670, https://doi.org/10.1017/s1464793103006419, 2004.

Yilmaz, P., Yarza, P., Rapp, J. Z., and Glöckner, F. O.: Expanding the World of Marine Bacterial and Archaeal Clades, Front. Microbiol., 6, 1524, https://doi.org/10.3389/fmicb.2015.01524, 2016.

Yin, Q., Fu, B., Li, B., Shi, X., Inagaki, F., and Zhang, X.H.: Spatial Variations in Microbial Community Composition in Surface Seawater from the Ultra-Oligotrophic Center to Rim of the South Pacific Gyre, PLoS One, 8, e55148, https://doi.org/10.1371/journal.pone.0055148, 2013.

Yooseph, S., Andrews-Pfannkoch, C., Tenney, A., McQuaid, J., Williamson, S., Thiagarajan, M., Brami, D., Zeigler-Allen, L., Hoffman, J., Goll, J. B., Fadrosh, D., Glass, J., Adams, M. D., Friedman, R., and Venter, J. C.: A metagenomic framework for the study of airborne microbial communities, PLoS One, 8, e81862, https://doi.org/10.1371/journal.pone.0081862, 2013.

Zhalnina, K., De Quadros, P. D., Gano, K. A., Davis-Richardson, A., Fagen, J. R., Brown, C. T., Giongo, A., Drew, J. C., Sayavedra-Soto, L. A., Arp, D. J., Camargo, F. A. O., Daroub, S. H., Clark, I. M., McGrath, S. P., Hirsch, P. R., and Triplett, E. W.: Ca. nitrososphaera and bradyrhizobium are inversely correlated and related to agricultural practices in long-term field experiments, Front. Microbiol., 4, 1-13, https://doi.org/10.3389/fmicb.2013.00104, 2013. 